\title{
Cyanoethylation of alcohols and amines by cesium-modified zeolite Y
}

\author{
Sara Zamanian, Ali Nemati Kharat* \\ School of Chemistry, University College of Science, University of Tehran, Tehran, Iran
}

\section{A R T I C L E I N F O}

\section{Article history:}

Received 22 August 2013

Accepted 13 November 2013

Published 20 February 2014

\section{Keywords:}

Modified Y zeolite

Basic catalyst

Cyanoethylation

Nano-particle

\begin{abstract}
A B S T R A C T
Zeolite Y modified by cesium and magnesium ions was prepared by ion-exchange and impregnation methods, and its activity in the cyanoethylation of aliphatic and aromatic alcohols and amines was investigated. During the preparation of some samples, the transformation of zeolite Y into a pollucite-type phase occurred. This phase exhibited good activity in the cyanoethylation of aliphatic alcohols. The prepared solids modified by the impregnation method were more active than the ion-exchanged solids. The activities of the catalysts, in contrast to other basic solids, were scarcely affected by the presence of air or moisture. A correlation between catalyst basicity and catalytic activity is discussed. The catalysts were characterized by X-ray diffraction, volumetric nitrogen adsorption surface area measurement, and $\mathrm{CO}_{2}$ temperature-programmed desorption. Scanning electron microscopy revealed that the particles of the modified nanocatalysts were $<40 \mathrm{~nm}$. The reaction of acrylonitrile with linear alcohols in the presence of the catalysts was accelerated by microwave irradiation.
\end{abstract}

(C) 2014, Dalian Institute of Chemical Physics, Chinese Academy of Sciences. Published by Elsevier B.V. All rights reserved.

\section{Introduction}

The catalytic addition of alcohols or amines to a carbon-carbon double bond provides a useful method for the preparation of ethers and amines [1]. Cyanoethylation, the addition of alcohols or amines with active hydrogen to acrylonitrile, has attracted significant interest for the synthesis of drug intermediates, plasticizers, insecticides, emulsifiers, additives for synthetic rubber, and physiologically active compounds [2]. The resulting nitriles can be converted to different types of amines after hydrogenation or can form the related carboxylic acid. Usually, cyanoethylation can be promoted in the presence of a base [2,3]. The homogeneous basic catalysts $[2,4]$ so far reported for the cyanoethylation of alcohols are alkali hydroxides [3], alkali alkoxides [4], tetraalkylammonium hydroxides [5], alkyl mercaptans, cresols, and partial pyrophosphate esters [6]. Neutralization of these soluble catalysts prior to purification of the product generates waste and reduces the product yields. In most cases, bleaching steps are necessary for the removal of color arising from impurities. Low selectivity is an additional problem.

Anion exchange resins have been used as heterogeneous catalysts for cyanoethylation reactions [7-9]. The problem associated with use of these resins is their deactivation after a few runs probably due to the formation of polyacrylonitrile layers on the surface. Hattori and Kabashima [10] studied the cyanoethylation of alcohols over alkali metal oxides, hydroxides, carbonates, and alumina-supported KF as basic catalysts. They found that magnesium oxide is a very active catalyst for the cyanoethylation of alcohols. In the last decade, modified layered double hydroxides (LDHs) have been used and show high catalytic activity in several reactions. The hydroxyl groups on surface of Mg-Al-OH layered double hydroxides are capable of acting as Brönsted basic sites in catalytic reactions such as

* Corresponding author. Tel: +98-21-61112499; E-mail: alnema@khayam.ut.ac.ir

DOI: 10.1016/S1872-2067(12)60751-7 | http://www.sciencedirect.com/science/journal/18722067 | Chin. J. Catal., Vol. 35, No. 2, February 2014 
cyanoethylation [11-16].

Zeolites are aluminosilicates constructed from $\mathrm{TO}_{4}$ tetrahedra (T: a tetrahedral unit built around $\mathrm{Si}$ and $\mathrm{Al}$ ) with apical oxygen atoms shared with neighboring tetrahedra, and these materials have great potential as basic catalysts and catalyst supports. While tetrahedra containing $\mathrm{Si}^{4+}$ and $\mathrm{Al}^{3+}$ are attached to form a three-dimensional zeolite framework, there is a negative charge associated with each $\mathrm{Al}^{3+}$ atom. The negative framework charge is balanced by an exchangeable cation, achieving electrical neutrality. The basicity of ion-exchanged zeolites arises from the negative charge on the framework [17].

Two approaches have been used to create basicity in zeolites. The first method uses ion-exchange with alkali metal ions. In this method, the nature of the alkali metal affects the basic strength of the modified zeolites. The second method employs impregnation of the zeolite pores with entities that can act as bases $[18,19]$.

In this research, we modified zeolite $Y$ with alkali metal ions by ion-exchange and impregnation methods. Zeolite $\mathrm{Y}$ is a three-dimensional zeolite with large cavities present in the structure that are interconnected by 12 member ring channels, which means that there are 12 cations $\left(\mathrm{Si}^{4+}\right.$ and $\left.\mathrm{Al}^{3+}\right)$ and $12 \mathrm{O}^{2-}$ anions present in the ring. These structural properties made it suitable as a selective heterogeneous catalyst [20].

Prepared catalysts were studied in the cyanoethylation of aliphatic and aromatic alcohols and amines. All the reactions were carried out at ambient temperature or under reflux conditions. Correlation of the catalytic performance with the physicochemical structure of the catalysts has been carried out.

The use of microwave ovens in synthetic chemistry has recently shown rapid growth [21-33]. After the first reports of microwave-assisted synthesis in 1986 [34,35], this technique has been widely accepted as a means of reducing reaction times [36-40]. To reduce the reaction time in our case, we carried out the cyanoethylation of aliphatic alcohols with acrylonitrile under microwave irradiation in the presence of the various catalysts.

\section{Experimental}

\subsection{Catalyst preparation}

All the reagents were used without further purification. $\mathrm{NaY}$ zeolite with a $\mathrm{SiO}_{2} / \mathrm{Al}_{2} \mathrm{O}_{3}$ molar ratio of 5 was prepared according to published methods [41,42]. $\mathrm{Cs}_{2} \mathrm{CO}_{3}$ and $\mathrm{Mg}\left(\mathrm{CH}_{3} \mathrm{CO}_{2}\right)_{2}$ were obtained from Merck. Magnesium oxide was prepared by the decomposition of magnesium acetate at elevated temperatures under vacuum. Cs-exchanged zeolite $\mathrm{Y}$ was prepared from the synthesized $\mathrm{NaY}$ using ion-exchange with cesium carbonate solution. A total of $5 \mathrm{~g}$ zeolite $\mathrm{Y}$ was suspended in $100 \mathrm{~mL}$ of $0.05 \mathrm{~mol} / \mathrm{L} \mathrm{Cs}_{2} \mathrm{CO}_{3}$ aqueous solution and stirred for $24 \mathrm{~h}$ at $70-80^{\circ} \mathrm{C}$. After filtration and washing twice with distilled water, the solid was dried overnight at $100^{\circ} \mathrm{C}$ and then calcined at $600{ }^{\circ} \mathrm{C}$ for $4 \mathrm{~h}$ (catalyst A). Catalyst B was prepared in a different way by mixing $\mathrm{NaY}$ zeolite with $\mathrm{Cs}_{2} \mathrm{CO}_{3}$ in a minimum amount of water on a steam bath. The mixture was stirred for $2 \mathrm{~h}$ whilst the water content remained constant.
Subsequently the mixture was allowed to dry on the steam bath. This sample was washed with a solution of methanol-water (1:1), then dried overnight at $100{ }^{\circ} \mathrm{C}$ and calcined at $600{ }^{\circ} \mathrm{C}$ for $4 \mathrm{~h}$. A portion of catalyst $\mathrm{B}(0.5 \mathrm{~g})$ was impregnated with a mixture of $\mathrm{MgO}(0.2 \mathrm{~g})$ in ethanol $(25 \mathrm{~mL})$ for $15 \mathrm{~min}$ in an ultrasonic bath at $25^{\circ} \mathrm{C}$. The solvent was removed by evaporation under vacuum, and then dried overnight at $100{ }^{\circ} \mathrm{C}$ and calcined at $600{ }^{\circ} \mathrm{C}$ for $4 \mathrm{~h}$ (catalyst C). For preparation of catalyst $\mathrm{D}$, the pores of catalyst $\mathrm{A}(0.5 \mathrm{~g})$ were impregnated with a mixture of $\mathrm{MgO}(0.2 \mathrm{~g})$ in ethanol $(25 \mathrm{~mL})$ for $15 \mathrm{~min}$ in an ultrasonic bath at $25{ }^{\circ} \mathrm{C}$. The solvent was removed by evaporation under vacuum, after which the solid was dried overnight at $100{ }^{\circ} \mathrm{C}$ and then calcined at $600{ }^{\circ} \mathrm{C}$ for $4 \mathrm{~h}$.

The cesium and magnesium contents of the catalysts were determined using an ICP-OES (Varian Vista-MPX) spectrometer. Catalysts A, B, C, and D contained 13\%, 40.2\%, 35.3\%, and $8.5 \%$ cesium, respectively. The contents of magnesium in catalysts $\mathrm{C}$ and D were $9.1 \%$ and $11 \%$, respectively.

\subsection{Catalyst characterization}

The structure and phase purity of all synthesized zeolites were monitored by powder X-ray diffraction (XRD) using a Bruker D8 ADVANCE diffractometer using $\mathrm{Cu} K_{\alpha}$ radiation. The scanning range of $2 \theta$ was set between $5^{\circ}$ and $50^{\circ} . \mathrm{N}_{2}$ adsorption/desorption isotherms were obtained at $-196^{\circ} \mathrm{C}$ using a BELSORP-mini II surface area measurement system after degassing the samples under vacuum at $300{ }^{\circ} \mathrm{C}$ overnight. The surface areas of all samples were calculated using the BET methodology. The surface morphology of the catalysts was obtained on a Zeiss DSM-960A scanning electron microscope (SEM) with an acceleration voltage of $10 \mathrm{kV}$.

Temperature-programmed desorption (TPD) studies of synthesized catalysts were carried out using $\mathrm{CO}_{2}$ as a probe for determining the number and strength of active basic sites. $\mathrm{CO}_{2}$-TPD analysis was performed on a ChemBET-3000 (Quantachrome) instrument. The TPD desorption ramp of the chemically adsorbed $\mathrm{CO}_{2}$ was run from 50 to $1000{ }^{\circ} \mathrm{C}$ with a heating rate of $10{ }^{\circ} \mathrm{C} / \mathrm{min}$ using helium as the carrier gas. The catalyst sample $(0.103 \mathrm{~g})$ with a particle size of $60-80 \mu \mathrm{m}$ was held in a plug flow quartz reactor that was coupled to a thermal conductivity detector (TCD). The catalyst samples were degassed under a nitrogen flow $(10 \mathrm{~mL} / \mathrm{min})$ at constant heating rate $\left(10{ }^{\circ} \mathrm{C} / \mathrm{min}\right)$ to $500{ }^{\circ} \mathrm{C}$ and held at the final temperature for $1 \mathrm{~h}$. Then, a stream of $\mathrm{He} / \mathrm{CO}_{2}$ with a $19 / 1$ feed ratio was passed over the catalyst bed for $20 \mathrm{~min}$ at $50{ }^{\circ} \mathrm{C}$ and finally flushed with helium for $1 \mathrm{~h}$ at $50^{\circ} \mathrm{C}$. For the determination of the identity and purity of reaction products, a mass spectrometer and a gas chromatograph (GC-MS), Agilent model 7890A with an HP-5 capillary column and an FID detector were used.

Microwave reactions were carried out using a Samsung domestic microwave oven operating at $2.45 \mathrm{GHz}$ with a PTFE closed container of $15 \mathrm{~mL}$ capacity as the reaction vessel.

\subsection{Reaction procedure}

Different alcohols or amines (76 mmol, excess amount), ac- 
rylonitrile (19 $\mathrm{mmol})$, and catalyst ( $0.06 \mathrm{~g})$ were added to a round bottomed flask and were stirred under argon at room temperature for $24 \mathrm{~h}$. This reaction was performed in the presence of $1 \mathrm{~mL}$ of toluene as solvent under reflux condition for $6 \mathrm{~h}$.

To a microwave vessel containing the required quantities of aliphatic alcohols and acrylonitrile, $0.06 \mathrm{~g}$ of catalyst $\mathrm{C}$ was added. The vessel was sealed and irradiated for 5 and $15 \mathrm{~min}$ using a power level of $900 \mathrm{~W}$. After separation of the catalyst by centrifuging, the products were analyzed by GC-MS. Conversions were periodically determined using $n$-decane as an internal standard.

The separated catalyst was washed with ethanol and water and dried at $100{ }^{\circ} \mathrm{C}$ overnight then calcined at $300{ }^{\circ} \mathrm{C}$ for $4 \mathrm{~h}$. All reactions were carried out on the recovered catalyst, which showed only a small loss of activity after being reused four times.

\section{Results and discussion}

The general reaction scheme for the cyanoethylation of alcohols and amines is shown in Scheme 1. This type of reaction requires a basic catalyst, and so activities reflect the basic character of the prepared catalysts. The results of cyanoethylation reactions of alcohols and amines are summarized in Table 1.

No appreciable activity was seen at room temperature after $24 \mathrm{~h}$ and under reflux after $6 \mathrm{~h}$ for linear aliphatic alcohols, or for phenol as an aromatic alcohol in the presence of catalyst A, but aniline showed a low conversion at ambient temperature and moderate conversion under reflux. The conversion of acrylonitrile in the reaction with hexylamine and diethylamine increased up to $100 \%$ in the presence of the prepared catalysts either at the room temperature or under reflux, which was expected because of the higher basicity of amines with respect to alcohols. Catalyst B, which is active for cyanoethylation of linear aliphatic alcohols, showed no activity for the reaction of phenol with aniline.

$$
\begin{aligned}
& \mathrm{R}-\mathrm{XH}+\mathrm{H}_{2} \mathrm{C}=\mathrm{CH}-\mathrm{CN} \stackrel{\substack{\text { Base } \\
\text { catalyst }}}{\mathrm{X}=\mathrm{O}, \mathrm{NH}} \\
& \mathrm{R}
\end{aligned}-\mathrm{X}-\stackrel{\mathrm{C}}{\mathrm{C}}-\mathrm{C}^{\mathrm{H}}-\mathrm{CN}
$$

Scheme 1. Cyanoethylation of alcohols and amines to related nitriles.

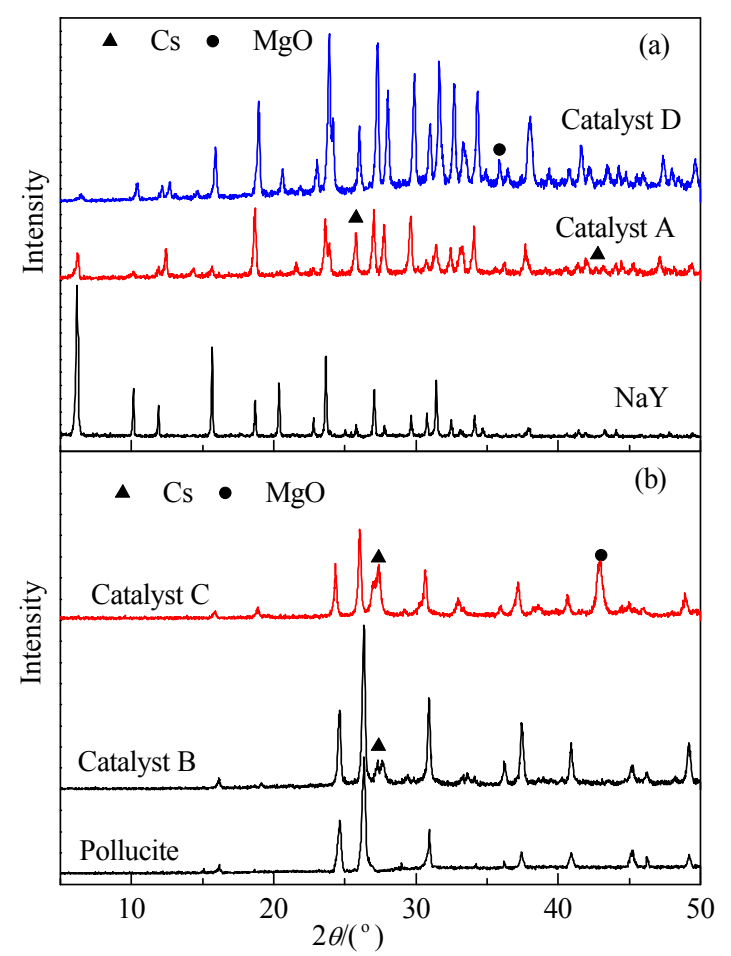

Fig. 1. Comparison of powder XRD patterns of (a) synthesized catalysts A and D based on zeolite $\mathrm{NaY}$ and (b) synthesized catalysts B and C with pollucite.

Comparison of acrylonitrile conversions on catalysts A and B showed that, with impregnation of $\mathrm{NaY}$ zeolite by cesium carbonate, a more basic catalyst was obtained compared with the ion-exchanged solid. It would appear that the high alkalinity of cesium carbonate transformed the framework of Y zeolite, a FAU type structure with 12-membered rings into a pollucite-type phase, an ANA type zeolite with distorted 8-ring pores. XRD diffraction traces in Fig. 1 show that upon impregnation of the zeolite with cesium carbonate (catalyst $\mathrm{B}$ ), the zeolite Y structure is destroyed and the peaks related to pollucite phase appear (Powder Diffraction File No. 29-0407, International Centre for Diffraction Data (ICDD), Newton Square, $\mathrm{PA})$. Pollucite is a cesium aluminosilicate $\left(\mathrm{CsAlSi}_{2} \mathrm{O}_{6}\right)$ and is commercially the most important cesium-bearing ore. Peaks around $2 \theta=26^{\circ}$ in Fig. 1(b) indicate the presence of excess cesium ions in catalyst $\mathrm{B}$. The effect of the cesium ion in im-

Table 1

Conversion of acrylonitrile in the presence of prepared catalysts for various reactants.

\begin{tabular}{lccccccrrr}
\hline \multirow{2}{*}{ Catalyst } & \multicolumn{9}{c}{ Conversion (\%) } \\
\cline { 2 - 9 } & Methanol & Ethanol & Propanol & Butanol & Phenol & Aniline & Hexylamine & Diethylamine \\
\hline None & 0 & 0 & 0 & 0 & 0 & 0 & 91 & 65 \\
$\mathrm{~A}$ & 0 & 0 & 0 & 0 & 0 & 8.4 & 98 & 87 \\
$\mathrm{~A}^{\text {a }}$ & 0 & 0 & 0 & 0 & 0 & 40 & 100 & 100 \\
$\mathrm{~B}$ & 87.4 & 85.2 & 77.3 & 62.2 & 0 & 0 & 92 & 75 \\
$\mathrm{~B}$ a & 99.7 & 99.3 & 99.5 & 95.9 & 75 & 5.3 & 100 & 100 \\
$\mathrm{C}$ & 96.1 & 89.7 & 17.1 & 8.5 & 0 & 0 & 90 & 70 \\
$\mathrm{C}$ a & 99.4 & 98.5 & 97.6 & 95.7 & 46 & 0.8 & 100 & 100 \\
D & 0 & 0 & 0 & 0 & 0 & 17.8 & 95 & 95 \\
D a & 0 & 0 & 0 & 0 & 0 & 92 & 100 & 100 \\
\hline
\end{tabular}

a Under reflux for $6 \mathrm{~h}$ 
proving the basic character of solid catalysts has been mentioned elsewhere [43]. The effect is related to the large ionic radius, low charge density, and the high polarizability of the cesium cation.

An interesting point concerns the cyanoethylation activity of the prepared catalysts for aniline and phenol (Table 1). The heterogeneously catalyzed cyanoethylation reaction of alcohols and amines proceeded by two different mechanisms (Scheme 2).

In the first mechanism, alcohols are activated by the solid catalyst producing alkoxide species, whereas in the second mechanism, in the reaction with amines, acrylonitrile was adsorbed and activated on the catalyst surface. The basicity of catalyst B is probably sufficient for deprotonation of alcohols with subsequent attack of the alkoxide to form acrylonitrile, which then forms the 3-alkoxypropanenitrile anion followed by adsorption at surface proton centers to produce the final product (mechanism 1) [10]. For reaction with amines, adsorbed acrylonitrile was affected by the high electrostatic field of the alkali ions on the surface of the ion-exchanged zeolite. This produced an electron-deficient center at the $\beta$-carbon of acrylonitrile, and even aniline with its relatively low nucleophilicity could attack the double bond (mechanism 2) [44].

The surface areas and pore volumes of all samples are listed in Table 2. Surface areas of NaY zeolite decreased from 720 to 583 and to $194 \mathrm{~m}^{2} / \mathrm{g}$ for catalysts $\mathrm{A}$ and $\mathrm{B}$, respectively. The total pore volumes fell from 0.3 to $0.25 \mathrm{~cm}^{3} / \mathrm{g}$ for catalyst A and to $0.02 \mathrm{~cm}^{3} / \mathrm{g}$ for catalyst $\mathrm{B}$, which confirms the presence of more basic sites on the internal and external surface of catalyst $\mathrm{B}$ and the phase transformation of zeolite $\mathrm{Y}$ to pollucite. In cat-

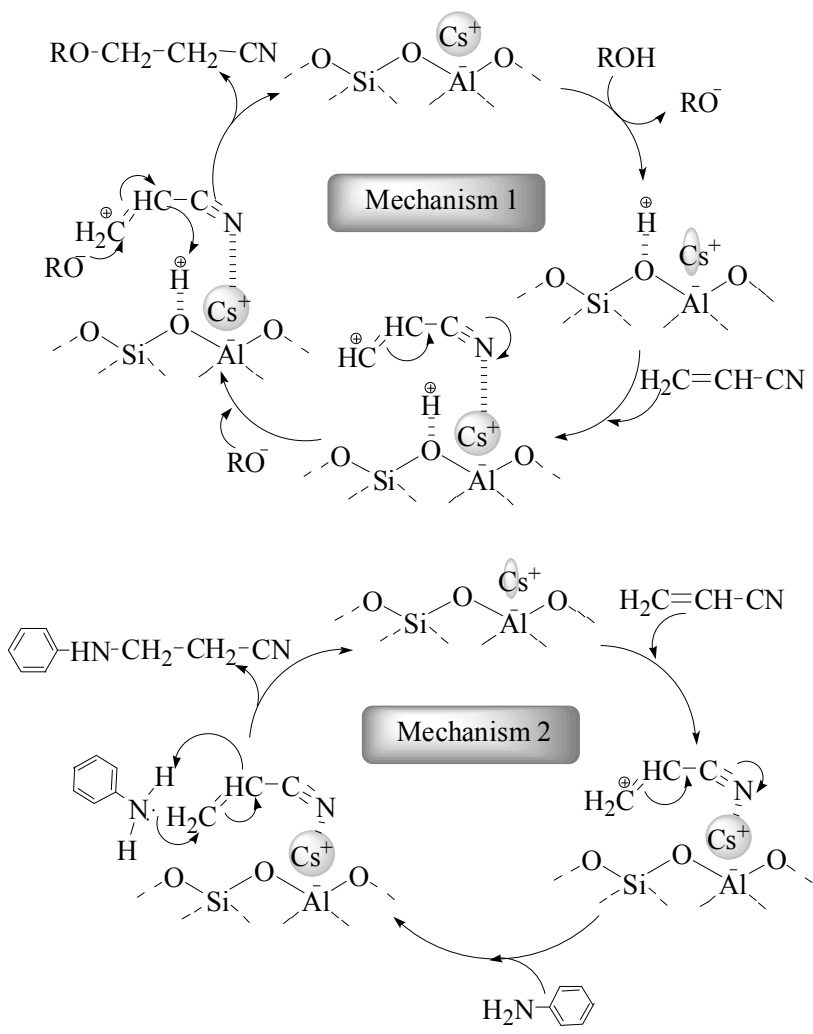

Scheme 2. A plausible mechanism for the cyanoethylation of alcohols and amines over the catalysts.
Table 2

Comparison of the surface area and pore volume of synthesized catalysts.

\begin{tabular}{lcc}
\hline Catalyst & Surface area $\left(\mathrm{m}^{2} / \mathrm{g}\right)$ & Pore volume $\left(\mathrm{cm}^{3} / \mathrm{g}\right)$ \\
\hline $\mathrm{NaY}$ & 720 & 0.30 \\
$\mathrm{~A}$ & 583 & 0.25 \\
$\mathrm{~B}$ & 194 & 0.02 \\
$\mathrm{C}$ & 182 & 0.08 \\
$\mathrm{D}$ & 436 & 0.02 \\
\hline
\end{tabular}

alyst B, cesium ions entered the pores of the zeolite and significantly reduced the surface area and pore volume. Catalyst B had a higher basicity than catalyst $\mathrm{A}$ and showed higher activity in the cyanoethylation of alcohols, even for phenol (under reflux conditions).

The higher basicity of catalyst $\mathrm{C}$, associated with its higher catalytic activity, was confirmed by $\mathrm{CO}_{2}$-TPD. This technique is a suitable tool for obtaining information about the activity and distribution of active sites in zeolites. In Fig. 2, TPD profiles for all samples are shown. The first maxima of catalysts B and C appeared at 580 and $690{ }^{\circ} \mathrm{C}$, respectively, which are much higher than for catalyst $\mathrm{A}\left(390^{\circ} \mathrm{C}\right)$ and catalyst $\mathrm{D}\left(440{ }^{\circ} \mathrm{C}\right)$. Higher maxima for the $\mathrm{CO}_{2}$ desorption temperature and the peak areas of catalysts $\mathrm{B}$ and $\mathrm{C}$ confirm that these catalysts have a higher basicity and a higher concentration of basic sites with respect to the other catalysts. The $\mathrm{CO}_{2}$-TPD profile of catalyst $\mathrm{C}$ shows that by introducing the $\mathrm{MgO}$ species into the pores of catalyst $B$, an increase in basicity was observed, but the concentration of the basic sites remained constant.

For catalyst $\mathrm{C}$, acrylonitrile conversion decreased with an increasing number of carbons in the molecule from methanol to butanol, in line with the relative alcohol acidities. The ease of proton abstraction with a base catalyst depends on alcohol acidity, implying that a higher acidity was associated with higher conversion levels. With catalyst B, no products were found from attempts to affect the cyanoethylation of phenol and aniline when the reactions were carried out at room temperature. Acceptable conversions were achieved with phenol in the presence of catalyst $C$ under reflux, but aniline was still unreactive under these conditions.

The addition of amines to $\alpha, \beta$-unsaturated compounds has

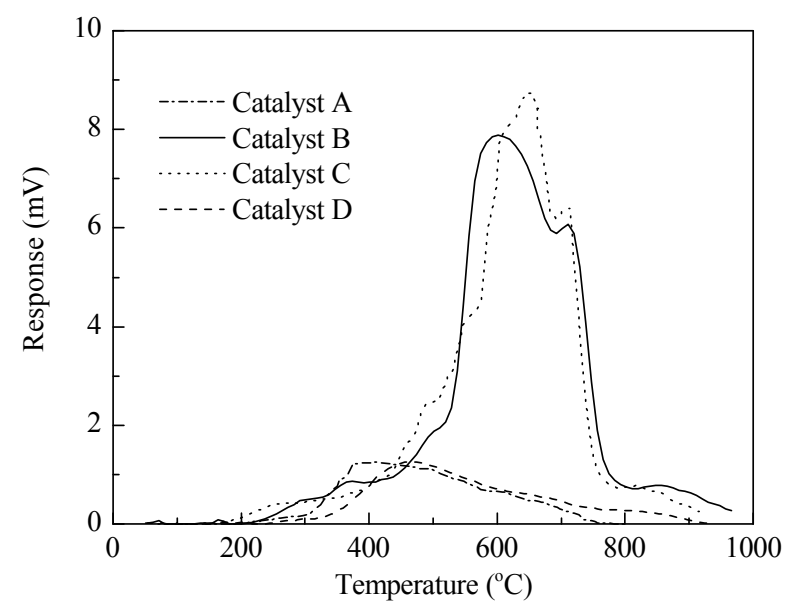

Fig. 2. TPD profiles of $\mathrm{CO}_{2}$ adsorbed on the catalysts. 
been extensively studied $[45,46]$, but aniline has been less used as the substrate in the reaction with $\alpha, \beta$-unsaturated compounds $[47,48]$. Homogenous catalysts and some Lewis acid catalysts have been used for this type of reaction, giving yields in the range 33\%-50\% [49,50], but heterogeneous systems based on zeolites have attracted much less attention. Our prepared zeolite-based catalysts showed conversions up to $90 \%$ for the cyanoethylation reaction with aniline.

According to mechanism 1 (Scheme 2), good reactivity with phenol needs high basicity. The low surface area and low total pore volume of catalyst $\mathrm{C}$ confirmed a high level of magnesium oxide loading into the catalyst pores and on its surface. New peaks appearing at $2 \theta=43.1^{\circ}$ in the XRD patterns of catalyst $C$ (Fig. 1(b)) indicate the existence of magnesium oxide in the framework.

Interestingly, catalyst D, which had no activity for cyanoethylation of alcohols, showed a low conversion at room temperature and a very high conversion under reflux conditions for aniline. In this case, precipitated $\mathrm{Mg}(\mathrm{OH})_{2}$ could increase the basicity of the catalyst, but the basicity present is insufficient to catalyze the cyanoethylation of alcohols. Catalyst D was the best sample for cyanoethylation of the less reactive aniline, with conversions of up to $90 \%$. It seems that catalyst D showed some similarity in reactivity for cyanoethylation with catalyst A. XRD patterns of catalysts A and D confirmed that the structure of zeolite $Y$ was preserved. New peaks at $2 \theta=25.7^{\circ}$ and $42.5^{\circ}$ in the XRD pattern of catalyst $\mathrm{A}$, in comparison with zeolite $\mathrm{Y}$, showed the presence of cesium in catalyst A. The low surface area of catalyst $\mathrm{D}$, related to the presence $\mathrm{MgO}$ in the pores, exhibited confirmatory new peaks at $2 \theta=35.8^{\circ}$ (Fig. 1(a)).

SEM images of all catalysts studied showed the presence of nanoparticles for all samples (Fig. 3). The highest conversion of acrylonitrile in reacting with linear alcohols was observed in the presence of catalysts $\mathrm{B}$ or $\mathrm{C}$ under reflux conditions. To reduce the reaction times further, the microwave-assisted technique was employed for the reaction in the presence of catalyst C. Methanol and ethanol reacted with acrylonitrile with good yields under microwave irradiation (Table 3), but no products were found for propanol. Increasing the microwave

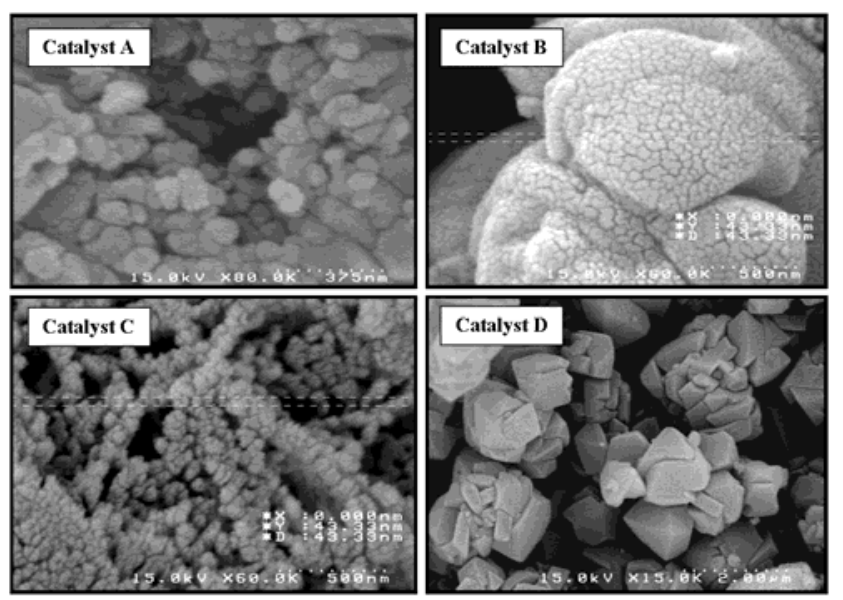

Fig. 3. SEM images of synthesized catalysts A, B, C, and D.

\section{Table 3}

Conversion (\%) of acrylonitrile in the presence of catalyst $\mathrm{C}$ under microwave irradiation for different reaction duration and microwave power level.

\begin{tabular}{|c|c|c|c|c|c|c|}
\hline \multirow{2}{*}{$\begin{array}{l}\text { Power } \\
\text { (W) }\end{array}$} & \multicolumn{2}{|c|}{ Methanol } & \multicolumn{2}{|c|}{ Ethanol } & \multicolumn{2}{|c|}{ Propanol } \\
\hline & $5 \mathrm{~min}$ & $15 \mathrm{~min}$ & $5 \mathrm{~min}$ & $15 \mathrm{~min}$ & $5 \mathrm{~min}$ & $15 \mathrm{~min}$ \\
\hline 900 & 83 & 98 & 34 & 77 & 0 & 0 \\
\hline 600 & 47 & 78 & 12 & 38 & 0 & 0 \\
\hline 300 & 13 & 42 & 0 & 23 & 0 & 0 \\
\hline
\end{tabular}

power and irradiation time might improve the conversions. The dielectric constant $(\epsilon)$ of methanol, ethanol, and propanol were extracted from the Dortmund Data Bank (www.ddbst. com/en/EED/PCP/DEC_C95.php).

The higher dielectric constant of methanol $(\epsilon=32.7)$ in comparison with ethanol $(\epsilon=24.3)$ and propanol $(\epsilon=20.1)$ leads to a higher reactivity under microwave irradiation.

\section{Conclusions}

Cesium and magnesium modified zeolite $\mathrm{Y}$ are active catalysts for the cyanoethylation of aliphatic and aromatic alcohols and amines. Modified heterogeneous basic solids with both cesium and magnesium showed higher activity than singly ion-exchanged catalysts. Owing to the strongly basic conditions obtained by the impregnation procedure leading to catalyst $\mathrm{B}$, the transformation of zeolite Y into a pollucite-type phase occurred, and the solid showed good activity in the cyanoethylation of aliphatic alcohols. The activities of the catalysts, unlike the other basic solids, were scarcely affected by the presence of air or moisture. It seems that the cyanoethylation of aniline, which followed a different mechanism, was well catalyzed by catalysts A and D. The SEM images of all catalysts showed particles with sizes $<40 \mathrm{~nm}$. Using microwave irradiation, the reaction times of acrylonitrile with linear alcohols were reduced to $15 \mathrm{~min}$ with good yields in the presence of basic heterogeneous catalysts.

\section{Acknowledgments}

The authors gratefully acknowledge the financial support from the University of Tehran.

\section{References}

[1] Hosokawa T, Shinohara T, Ooka Y, Murahashi S. Chem Lett, 1989, 18: 2001

[2] Bruson H L. Organic Reactions. Vol. 5. New York: John Wiley \& Sons, 1949. 79

[3] MacGregor J H, Pugh C. J Chem Soc, 1945: 535

[4] Mark H F, Othmer D F, Overberger C G, Seaborg G T. Kirk-Othmer: Encyclopedia of Chemical Technology. Vol. 7. New York: John Wiley \& Sons, 1979

[5] Utermohlen W P Jr. J Am Chem Soc, 1945, 67: 1505

[6] Reedy J D, Paugh P H. US Patent 3957 848. 1976

[7] Schmidle C J, Mansfield R C. Ind Eng Chem, 1952, 44: 1388

[8] Astle M J, Zaslowsky J A. Ind Eng Chem, 1952, 44: 2867

[9] Chen C S H.J Org Chem, 1962, 27: 1920 


\section{Graphical Abstract}

Chin. J. Catal., 2014, 35: 264-269 doi: 10.1016/S1872-2067(12)60751-7

\section{Cyanoethylation of alcohols and amines by cesium-modified} zeolite $\mathbf{Y}$

Sara Zamanian, Ali Nemati Kharat*

University of Tehran, Iran

Cesium-modified NaY prepared by ion-exchange or impregnation methods shows catalytic activity in the cyanoethylation reactions of various alcohols and amines.

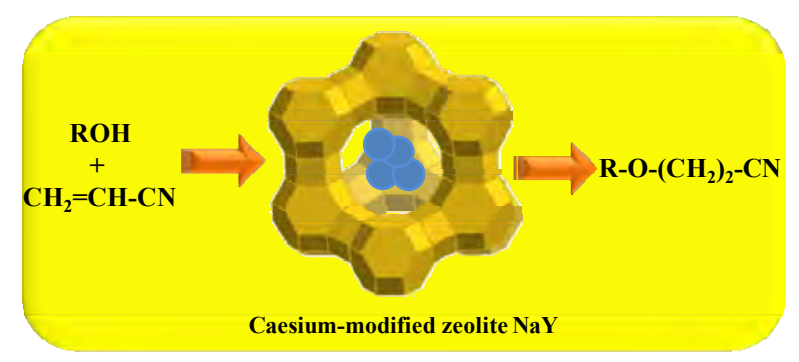

Gonzalez-Rivas N, Cuevas-Yañez E. Synthesis, 2012, 44: 2237

[30] Yu C W, Chen G S, Huang C W, Chern J W. Org Lett, 2012, 14: 3688

[31] Collados J F, Toledano E, Guijarro D, Yus M. J Org Chem, 2012, 77: 5744

[32] Baghbanzadeh M, Pilger C, Kappe C 0.J Org Chem, 2011, 76: 8138

[33] Talukdar D, Saikia L, Thakur A J. Synlett, 2011: 1597

[34] Gedye R, Smith F, Westaway K, Ali H, Baldisera L, Laberge L, Rousell J. Tetrahedron Lett, 1986, 27: 279

[35] Giguere R J, Bray T L, Duncan S M, Majetich G. Tetrahedron Lett, 1986, 27: 4945

[36] Westman J. Org Lett, 2001, 3: 3745

[37] Kuhnert N, Danks T N. Green Chem, 2001, 3: 68

[38] Loupy A, Regnier S. Tetrahedron Lett, 1999, 40: 6221

[39] Danks T N. Tetrahedron Lett, 1999, 40: 3957

[40] Stadler A, Kappe C 0. Eur J Org Chem, 2001, 2001: 919

[41] Occelli M L, Robson H E. Zeolite Synthesis. Washington DC: American Chemical Society, 1989. 11

[42] Sherry H S. J Phys Chem, 1966, 70: 1158

[43] Wolfe J P, Buchwald S L. J Org Chem, 2000, 65: 1144

[44] Komura K, Hongo R, Tsutsui J, Sugi Y. Catal Lett, 2009, 128: 203

[45] Varala R, Alam M M, Adapa S R. Synlett, 2003: 720

[46] Bartoli G, Bosco M, Marcantoni E, Petrini M, Sambri L, Torregiani E. JOrg Chem, 2001, 66: 9052

[47] Siddiqui A A, Arora A, Siddiqui N, Misra A. Indian J Chem Sect B, 2005, 44: 838

[48] Loh T P, Wei L L. Synlett, 1998: 975

[49] Li K, Horton P N, Hursthouse M B, Hii K K. J Organomet Chem, 2003, 665: 250

[50] Li K, Phua P H, Hii K K. Tetrahedron, 2005, 61: 6237

[28] Mingos D M P, Baghurst D R. Chem Soc Rev, 1991 20: 1

[29] García-Muñoz Á, Ortega-Arizmendi A I, García-Carrillo M A, Díaz E, 